\title{
ASYMMETRICAL GONADAL DYSGENESIS IN A MALE PATIENT: A RARE CASE REPORT
}

Anilkumar Sirasagi ${ }^{1}$, Mirza Asif Baig²

\section{HOW TO CITE THIS ARTICLE:}

Anilkumar Sirasagi, Mirza Asif Baig. "Asymmetrical Gonadal Dysgenesis in a Male Patient: A Rare Case Report". Journal of Evolution of Medical and Dental Sciences 2015; Vol. 4, Issue 26, March 30; Page: 4531-4534, DOI: $10.14260 /$ jemds/2015/655

ABSTRACT: BACKGROUND: Asymmetric Gonadal dysgenesis (AGD) very rare intersex disorder seen in less than $5 \%$ of all intersex disorders. Asymmetric gonadal dysgenesis refers to individuals who have abnormal and symmetrical gonadal development, usually a differentiated gonad on one side and a steak gonad or steak testis on other side. The importance of identifying these lesions are important because risk of development of malignancy as high as $30 \%$, which always influenced by $y$ chromosome. CASE REPORT: A 21 year old male patient presented with left sided obstructed inguinal hernia with cryptorchidism. On exploratory laparotomy, uterus with bilateral adnexa and testis are seen. Microscopy revealed features of asymmetric gonadal dysgenesis. True hermaphroditism was the closest differential diagnosis and was excluded by the strict histological criteria necessary for diagnosis. CONCLUSION: Asymmetric gonadal dysgenesis is a rare disorder. The rare nature of this entity and its clinical implications merits its reporting.

KEYWORDS: Asymmetric gonadal dysgenesis, cryptorchidism, gonadoblastomas.

KEYMESSAGES: Asymmetric gonadal dysgenesis is a rare disorder. It is important to diagnosis this entity because $30 \%$ of cases progress to gonadoblastomas. The rare nature of this entity and its clinical implications merits its reporting.

INTRODUCTION: Disorders of sex development are very complex diseases. Most of these disorders are congenital conditions in which development of anatomical, chromosomal or gonadal sex are atypical. True incidence in India is not known. In western countries it is as high as 1 in 2000 live birth. Asymmetric gonadal dysgenesis [AGD] is one of rare entities and part of intersex disorders accounts for $7 \%$ of all intersex disorders. ${ }^{1,2}$

AGD refers to individuals who usually have a differentiated gonad on one side and a streak gonad or streak testis on other side. Few authors apply the term to patients who show testicular differentiation on either side, bilateral streak testis or bilateral dysgenetic testis or gonadoblastomas on other side. They usually present as symptomatic male phenotype. In asymptomatic patients the diagnosis may delayed till their adult life. Rarely they it is incidental finding in the male or female phenotypes. ${ }^{1,2,3}$

CASE HISTORY: A 21 Years old married male patient and father of 2 children, presented with acute lower abdomen pain to emergency unit. On examination, bilateral cryptorchidism and mass in left inguinal canal noted. He had a male phenotype with well develop secondary sexual characters. External genitalia were normal. Ultra sonogram of abdomen and pelvis revealed bilateral cryptorchidism and obstructed inguinal hernia. Semen analysis, karyotyping and other investigations were not done since patient presented with surgical emergency and clinically it was not suspected. On exploratory laparotomy, uterus with bilateral fallopian tubes and ovaries were noted and was sent for histopathological examination. 


\section{CASE REPORT}

Macroscopically Uterus measures $8 \times 5 \times 4 \mathrm{~cm}$, both tubes measures $4 \mathrm{cms}$ and? ovaries $2.5 \times 2 \times 1 \mathrm{~cm}$ (Pic. 1). Microscopic examination of uterus and both side fallopian tubes showed normal histology. Section studied through globular tissue attached to fallopian tubes show vas-deference and epidydemal and seminiferous tubular structures (Pic. 2). No ovarian stroma or primordial follicles are seen. Section studied through separately sent testicular biopsy show features of incomplete spermatocytic maturation arrest (Pic. 3). A Diagnosis of Asymmetrical gonadal dysgenesis was made and advised for bilateral gonadectomy since chances for development of malignancy in gonads are very high. However we lost the follow up the case.

Fig. 1: Uterus with both side fallopian tubes and ovary like nodular structure.

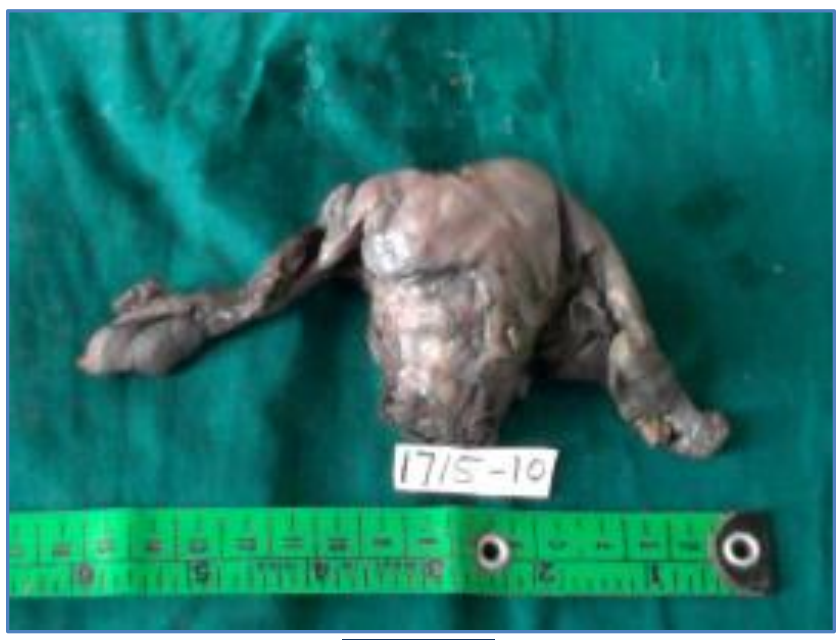

\section{Fig. 1}

Fig. 2: Microscopic picture shows adjacent to fallopian tube, vas deference and epidydemis structures seen. (10X).

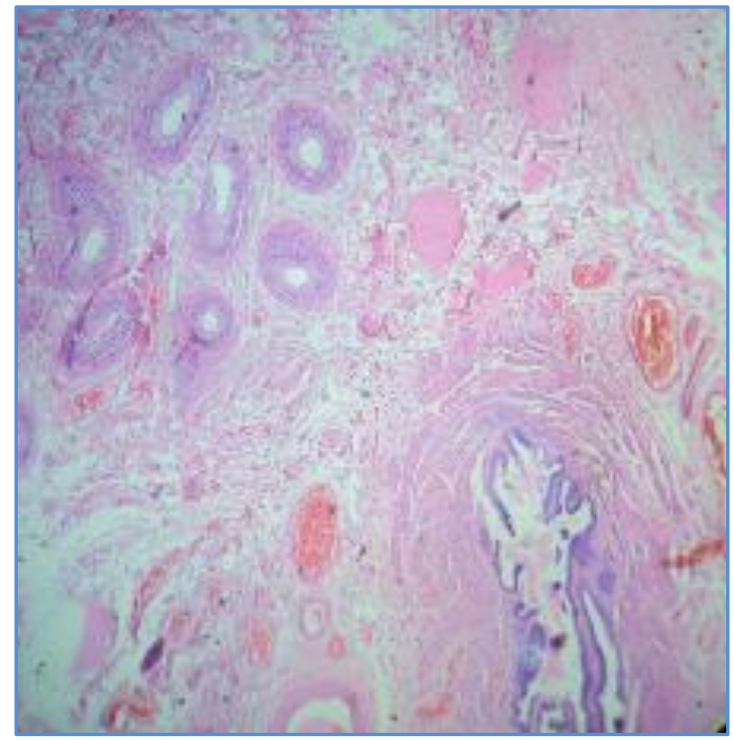

Fig. 2 


\section{CASE REPORT}

Fig. 3: Testicular biopsy shows atrophied seminiferous tubules with Incomplete Spermatocytic Maturation Arrest. (40X).

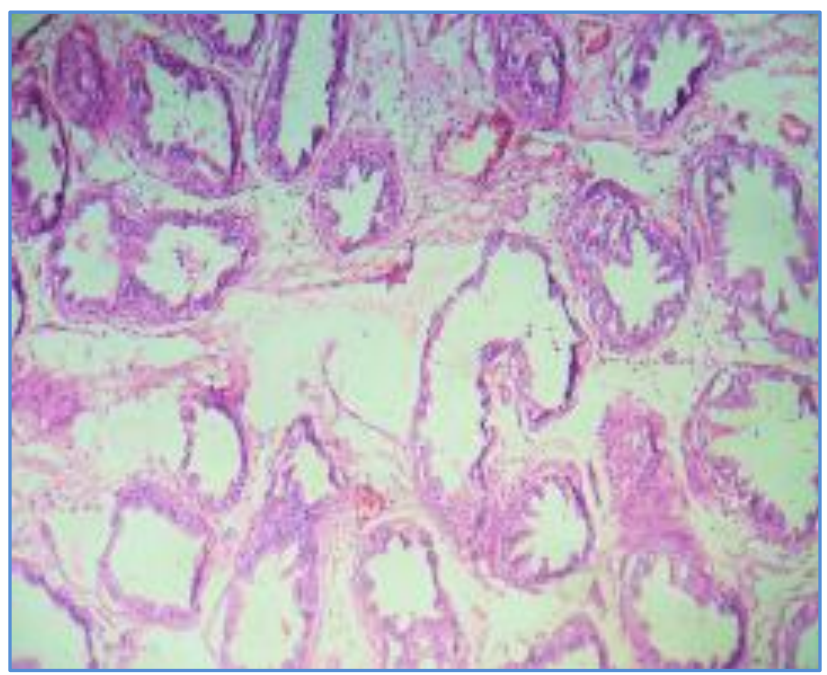

Fig. 3

DISCUSSION: Children born with intersex disorder comprise about 1.7\% of all live birth in western literature. Asymmetrical Gonadal Dysgenesis is one of the rare and important intersex disorder constitutes around $5-7 \%$ of all intersex disorders. The exact incidence in India is not known. This disorder diagnosed if one side gonad shows more complete development and can be identified as an ovary or testis (usually testis) and other side gonad is streak or malignancy.1,2,4

Majority of patients with Asymmetrical gonadal dysgenesis have testicular tissue on one side and and a steak gonad or steak testis on other side. Some authors reserve the term MGD for patients who have 45X/46XY karyotype with testis on one side and streak ovary on the other side.5,6,7 Other apply the term to all patients with varying degree of AGD with testicular differentiation on either side, bilateral streak testis or bilateral dysgenetic testis and karyotyping will be done in female phenotype patient or for research purpose. In our case karyotyping is not done due, due to loss of follow up. However the presence of testis which in-turn indicates presence of y chromosome. Latter identification is must since it influences the development of gonadoblastomas in later age.

Persistent Mullerian duct syndrome is excluded base upon macroscopic and microscopic findings. True hermaphroditism was the closest differential diagnosis and was excluded by the strict histological criteria necessary for diagnosis i, e absence of seminiferous tubules with immature sertoli cells and few primitive germs cell and ovarian stroma comprised of numerous primordial or mature follicles containing primary oocytes adjacent to the fallopian tube. It is important to differentiate the two condition because it is necessary for gender assignment and in AGD 30\% patients develop germ cell tumors like dysgerminoma, yolksac tumor, Embryonal carcinoma and hence gonadectomy is necessary in such cases.7,8 The diagnosis of pseudohermaphroditism due to endocrine disorders and true hermaphroditism was excluded on clinical and histological grounds. 
CONCLUSION: Asymmetric gonadal dysgenesis is rare phenomenon and it is important to diagnose this entity in early age because of proper gender assignment and $30 \%$ of these cases progress to Gonadoblastomas. The very rare nature of this entity and medical significance merits its reporting.

\section{REFERENCES:}

1. Leigh B. Gonadal dysgenesis Gynakol Geburtsmed Gynakol Endokrinol 2009; 5(2): 82-94 published 31.07.09. www.akademos.de/gyn Cakademos Wissenschaftsverlag 2009 ISSN 16148533.

2. Mixed Gonadal Dysgenesis in http://humpath.com/spip.php?article7943.Last modified: 12 July 2011.

3. Kyu-Rae Kim, Youngmee Kwon, Jae Young Joung, Kun Suk Kim, Alberto G Ayala and Jae Y Ro. True hermaphroditism and mixed gonadal dysgenesis in young children. A clinicopathologic study of 10 cases. Mod Pathol 2002; 15(10):1013-1019.

4. Scully RE, Young RH. Tumors of the ovary mal developed gonads, fallopian tubes and broad ligaments atlas of tumor pathology. 3rd series Washington. 1998. p.399-408.

5. Blackless M, Charuvastva A, Derrycka, and Lee E. How sexually dimorphic are we? review and synthesis. Am J Hum Biolo. 2000; 12: 151-166.

6. Blanco JA, Martínez-Mora J, Granada M, Toran N, Isnard RM, Castellví A, Casasa JM. The mixed gonadal dysgenesis. Diagnostic criteria and surgical treatment. Cir Pediatr. 1997 Jan; 10(1): 34-7.

7. Plouffel MC, Donough PG. Ovarian Agenesis and Dysgenesis IN: Adashi Ey, Rockja. Editor. Reproductive Endocrinology surgery and technology. Philadelphia; Lippincott 1996 p.1366-84.

8. Kini U, Bantwal G, Ayyar V, Idiculla J. Bilateral gonadoblastomas with a left sided dysgerminoma in a true hermaphrodite (disorder of sexual differentiation) with 46, XY karyotype. J Assoc Physicians India. 2008 Jul; 56: 549-51.

\section{AUTHORS: \\ 1. Anilkumar Sirasagi \\ 2. Mirza Asif Baig}

\section{PARTICULARS OF CONTRIBUTORS:}

1. Associate Professor, Department of Pathology, ESIC Medical College, Sedam Road, Gulbarga, Karnataka, India.

2. Former Assistant Professor, Department of Pathology, BLDEU's, Sri B. M. Patil Medical College, Solapur Road, Bijapur, Karnataka, India.

FINANCIAL OR OTHER COMPETING INTERESTS: None

\section{NAME ADDRESS EMAIL ID OF THE CORRESPONDING AUTHOR:}

Dr. Anilkumar Sirasagi,

Associate Professor,

Department of Pathology,

ESIC Medical College,

Sedam Road, Gulbarga-585106.

Karnataka, India.

E-mail: dranilss09@gmail.com

Date of Submission: 02/03/2015.

Date of Peer Review: 04/03/2015.

Date of Acceptance: 18/03/2015.

Date of Publishing: 30/03/2015. 